Personality and Disruptive Behaviour

\title{
A Personality Approach to Understanding Disruptive Behaviour in the Classroom
}

\author{
Liam Paul Satchell ${ }^{\mathrm{a}}$, \\ Email: liam.satchell@winchester.ac.uk \\ Arif Mahmud ${ }^{\mathrm{b}}$, \\ Email: arif.mahmud@roehampton.ac.uk \\ Frances Warren ${ }^{\mathrm{a}}$, \\ Email: frances.warren@winchester.ac.uk \\ Sherria Hoskins ${ }^{c}$ \\ Email: sherria.hoskins@ port.ac.uk
}

${ }^{a}$ Department of Psychology, University of Winchester, Winchester, UK

${ }^{\mathrm{b}} \mathrm{S}$ chool of Education, University of Roehampton, London, UK

${ }^{c}$ Faculty of Science, University of Portsmouth, Portsmouth, UK

\section{Author's note:}

All data and analysis code can be found on the Open Science Framework, here: https://osf.io/u2br4/?view_only=b3a8ac2ce2e84888904442dfcd9b44d7

\footnotetext{
${ }^{1}$ Correspondence concerning this article should be addressed to Liam Satchell, liam.satchell@ winchester.ac.uk, University of Winchester, Sparkford Road, Winchester, Hampshire, UK, SO22 4NR
} 
Personality and Disruptive Behaviour

\title{
A Personality Approach to Understanding Disruptive Behaviour in the Classroom
}

\begin{abstract}
Background. Teachers report that disruptive behaviour in their classrooms consumes a significant amount of their time and attention. Research studying disruptive behaviour often focuses on differences between those pupils who meet categorical diagnostic criteria for developmental disorders and those who do not. However, there is much to be learned about disruption from a normative personality approach to individual differences.
\end{abstract}

Aims. This study investigates the relationship between personality traits and self- and teacherreported disruptive behaviours.

Sample. A sample of 457 pupils from two English state secondary schools were recruited.

Methods. Our analysis focuses on the relationship between self- and teacher-reported disruptive behaviour, and three measures of personality: Empathy, Reinforcement Sensitivity Theory, and Implicit Theories of Intelligence.

Results. Teachers reported less disruptive behaviour compared to the self-reports. Disruptive behaviour (measured via both self- and teacher-report) had negative relationships with empathy and incremental learning beliefs. Common variance latent factors across the personality models (Avoidance, Empathy, and Responsiveness) were related to disruptive behaviour.

Conclusions. These findings reinforce the importance of understanding disruptive behaviours from a normative individual differences perspective and have implications for research and practice.

Keywords: Disruptive Behaviour; Reinforcement Sensitivity Theory; Implicit Theories; Empathy; Classroom Behaviour 
Personality and Disruptive Behaviour

\section{A Personality Approach to Understanding Disruptive Behaviour in the Classroom}

\section{Introduction}

Disruptive behaviour can be considered 'behaviour that seriously interferes with the teaching process, and/or seriously upsets the normal running of the classroom' (Lawrence, Steed \& Young, 1983, p.83) and is a pervasive problem in school classrooms. In fact, the disruptive behaviour of pupils is a notable cause of job stress and burnout for teachers (see Aloe, Shisler, Norris, Nickerson \& Rinker, 2014). Research suggests that $10-20 \%$ of classes have pupils who routinely engage in disruptive behaviour and a teacher can spend up to $76 \%$ of their time addressing behavioural difficulties (Infantino \& Little, 2005). This is a concern for more than half of secondary school (11-16 year old pupils) teachers who report that they spend too much time on maintaining order and control in their classrooms (Houghton, Wheldall \& Merrett, 1988). It is rarely the case that disruptive behaviour involves violent acts towards peers or the teacher (Beaman, Wheldall \& Kemp, 2007; Little, 2005), but minor breaches of authority, such as talking or being out of seats, occur often and can be problematic for classroom control (Little 2005; Wheldall, 1991). Despite the fact that disruptive behaviour can make a teacher's job more difficult and more stressful, there has been surprisingly limited research investigating why pupils engage in disruptive behaviours. Research has studied the impact of those meeting the criteria of classified disorders, such as Attention Deficit Hyperactivity Disorders (ADHD), on disruptive behaviour (for example Abikoff et al., 2002), but there has been little research studying disruptive behaviour in typically developing children from a normative perspective (c.f. Rosyle Wilkinson \& Jones Bartoli, 2020). As a result, the relevance of non- (or sub-)clinical individual differences to engaging in disruptive behaviours is not well understood. The current study brings together multiple theories of personality and individual differences to investigate correlates of disruptive classroom behaviour.

Personality traits. There is little extant literature that has explored the relationship between personality and disruptive behaviour in schools. If certain personality traits predict disruptive behaviour, then identification of these traits would allow teachers to recognise 'at risk' pupils early and thus be able to more accurately target behaviour interventions. Moreover, there are potential strategies for managing 
Personality and Disruptive Behaviour

environments to better suit the disposition of pupils and mitigate risks to disruption. Therefore, we will set out to investigate the relationship between disruptive behaviour and personality using the following four theories of personality which explain interpersonal preferences and reward seeking behaviours in 1116-year olds.

Implicit theories of intelligence. It is logical to infer that those pupils who are disengaged from the value of learning might be those who are more likely to be disruptive. With this in mind, our first measure of individual differences is based on the Implicit Theories of Intelligence literature. Dweck (1986; 1999) argues that individuals generally orient towards one of two distinct sets of beliefs regarding the malleability of personal traits and characteristics. In the case of intelligence, Carol Dweck (e.g. Dweck, 1999; Dweck \& Leggett, 1988) posits that that some pupils believe that they can continually grow, learn, and develop their intelligence (holding an 'Incremental Theory' of intelligence), while others believe that intelligence is invariant and cannot be improved upon (endorsing an 'Entity Theory' of intelligence). Implicit Theories of Intelligence have been shown to have consequences for academic performance and persistence, with some evidence suggesting that holding an incremental theory has a positive impact on academic success (e.g. Blackwell, Trzesniewski \& Dweck, 2007; Warren et al., 2019) and other replications (Li \& Bates, 2020) and meta-analyses (Sisk, Burgoyne, Sun, Butler \& Macnamara, 2018) not.

Incremental theorists are said to orient towards 'learning goals' (Dweck \& Elliot, 1983; Elliott \& Dweck, 1988; Hoskins, 2019) with the aim to increase competence and take opportunities for challenge in order to develop their skills. Entity theorists are thought to place more emphasis on 'performance goals', tending to avoid challenges through the use of various self-protection strategies. For example, work on 'laddishness' has shown that those pupils who struggle with academic settings (perhaps holding an Entity theory of intelligence) can engage in anti-school behaviour to draw attention away from (perceived) lack of scholastic improvement (Jackson, 2002; 2003). The associations between Implicit Theories of Intelligence and protectionist behaviour strategies (i.e. giving up) would suggest that there are reasons to suspect that those who more strongly hold Entity Theories of Intelligence and support Incremental beliefs less may be those who are more inclined to disengage with the normal rules of conduct in the classroom and misbehave. 
Personality and Disruptive Behaviour

Empathy traits. Individual differences in social and interpersonal understanding can be studied using measures of empathic personality traits. These traits are relevant in the current study due to the social and interpersonal relation costs to disruptive behaviour. Research shows that peers will distance themselves from those who engage with disruptive behaviour (see Rubin, Coplan, Nelson, Cheah \& Lagace-Seguin, 1999) and teachers will also avoid contact with those who disrupt the class (Fry, 1983). Social exclusion from peers and avoidant behaviours by teachers are understandable consequences to disruption, however this leaves members of the classroom community socially excluded and separated from support. Therefore, we would expect those pupils who were more concerned about the opinions and feelings of others (and their teachers) to engage in less disruptive behaviour. Davis' (1980; 1983) model of empathy considers four main traits. The Empathic Concern where an individuals is affectively sensitive to the states of others, Perspective Taking and the ability to understand the thoughts and wants of others, Fantasizing and the ability to engage with empathic fiction, and Personal Distress and feeling overwhelmed by emotional situations. From this model we would expect those who score higher on traits associated with being empathetic are those who will engage in less disruptive behaviour.

Reinforcement Sensitivity Theory personality traits. There is evidence that clearly defined punishment and reward systems in a classroom can help address disruptive behaviours (Little, Hudson \& Wilks, 2002). Praise (as a reward) and reprimands (as punishment) have been shown to improve on-task behaviours in British schools (Houghton, Wheldall, Jukes \& Sharpe, 1990). Further research has shown that some deterrents and some incentives are seen as more effective than others (Houghton, Merrett \& Wheldall, 1988), however little work has investigated the effectiveness of reward and punishment on an individual level in the classroom. The Reinforcement Sensitivity Theory (RST) of Personality (see Corr, 2004) is a theory of personality oriented around how individuals respond to novel (rewarding or punitive) information in the environment. The RST personality traits are divided into dispositional avoidance behaviours (the Fight/Flight/Freeze system, 'FFFS'), trait approach behaviours (the Behavioural Approach System, 'BAS') and the tendency to pause and ruminate (the Behavioural Inhibition System, 'BIS'). This theory of individual differences could explain how pupils respond to reward and punishment in the classroom environment. Those pupils who are more inclined towards gaining reward (BAS) and more inhibiting (BIS) may be those who are less likely to misbehave. RST theorists have also considered 
Personality and Disruptive Behaviour

the relationship between ADHD and BIS (Corr \& McNaughton, 2015). It could also be the case that the rumination aspect of BIS could lead to longer lasting effects of punitive interactions with teachers, thus seeing a reduction in future disruptive behaviour.

The Big Five. One of the most popular theories of personality is the Big Five (McCrae \& Costa, 1987). The Big Five defines behaviour in terms of Conscientiousness (diligence and organisation), Agreeableness (sociality and amicability), Neuroticism (anxiety and worry), Openness to Experience (creativity and aesthetic interests) and Extraversion (energetics and confidence). This broad approach to defining personality has analogues to the aforementioned personality theories. Low Conscientiousness and high Neuroticism have been shown to relate to Entity Implicit Theories of Intelligence (Satchell, Hoskins, Corr \& Moore, 2017). Extraversion, and Neuroticism share conceptual roots with RST traits of BAS and BIS (both being developed from Eysenck \& Eysenck’s (1978) work; see Corr, 2004; McCrae \& John, 1992) and measures of the traits have been to correlate (Corr \& Cooper, 2016; Satchell et al., 2017). The Big Five traits of Agreeableness and Openness to Experience have also been shown to correlate with traits from Davis' model of empathy (De Corte et al., 2007). Given the broad scope of the Big Five, we include this model of personality to best capture various traits that may relate to disruptive behaviour; low learning diligence, low social and interpersonal skills, high levels of anxiety, and high energetics.

The current study. Here, we study the relationship between personality traits, and disruptive behaviours in 11-16 year old UK pupils. We have chosen personality theories that classify traits related to interpersonal behaviour, goal motivation, reward sensitivity and diligence. There are challenges with collecting objective reports of disruptive behaviour, so we measure disruptive behaviour using both teacher-reports and pupil self-reports. Whilst both reports have value, such as teachers perhaps having less report bias for individuals and the self-reports allowing for a more holistic account of behaviour, these are mitigated by their weaknesses- teachers not necessarily being fully aware of all incidences of disruption for all pupils and self-reports including positivity bias.

We hypothesise that participants who are less interpersonally sensitive (empathetic), less sensitive to rewards, more impulsive, more Entity theory oriented, and less anxious will be those who more often engage in self- and teacher-reported disruptive behaviour. We additionally predict that male participants will be self- and teacher-reported as more frequently engaging in disruptive behaviour, and this will 
Personality and Disruptive Behaviour

reflect gender differences in trait, with male pupils reporting lower empathy, lower reward sensitivity, lower endorsement of incremental theories of intelligence, and lower anxiety.

\section{Method}

Participants. A sample of 457 pupils were recruited from two UK secondary schools $(n=104$ and $n=353$ ) in a total of 24 class groups. The sample size for this study was an opportunity sample determined by the size of the schools we collaborated with. This sample size is sufficient to detect effects of $r=.17$, with the target power parameters of $\alpha=.05$ and $\beta=.05$. Due to missing points of data, some $N$ for analysis are lower than the overall total, but this is not lower than $N=392$ (teacher-reported behaviour).

Teacher-ratings of behaviour were provided by six different teachers for the six classes in one school and by 14 teachers for the 18 classes in the other school. All reports were provided by tutors who had pastoral roles for the students and knew them well. Consent was obtained from the schools, parents and participants before data collection took place. The schools admit pupils from a catchment area with a mixture of different socio-economic groups, representative of the typical and heterogeneous background of pupils in UK schools.

Procedure and materials. The study collected data in two parts. The pupils self-reported on their own personality and engagement in disruptive behaviours and teachers provided an independent report of pupils' behaviour.

Pupil self-report. The pupils all received a response booklet with the questionnaires. For ease of participant responding, the scale for responding to the four personality inventories was maintained as a 5point Agree to Disagree scale. Whilst this may be a change from the normal procedure deployed in some of these measures, all of the scales collect ranged scale responses and we do not compare our current sample's scores to existing norms.

The first questionnaire in the booklet was the 21-item Child Reinforcement Sensitivity Theory of Personality Questionnaire (C-RSTPQ; Cooper, Stirling, Dawe, Pugnaghi \& Corr, 2017). This questionnaire assesses traits responses to the core domains of Reinforcement Sensitivity Theory (RST); the Fight-Flight-Freeze System (FFFS) which relates to fear and avoidant behaviour, the Behavioural Inhibition System (BIS) which reflects trait anxiety and rumination behaviours and the Behavioural 
Personality and Disruptive Behaviour

Approach System (BAS) which is related to engagement and goal motivated activity. Previous research has shown good reliability of the FFFS $(\alpha=.76)$, BIS $(\alpha=.68)$ and BAS $(\alpha=.80)$ scales in pupils aged 913 years old (Cooper et al., 2016). The distribution of responses and internal reliabilities of the scales (using Mcdonald's $\omega$, computed using the 'jmv' R package, Selker, Love \& Dropmann, 2020) in this study can be found in table 1 .

The second questionnaire was the Interpersonal Reactivity Index (IRI, Davis, 1980). This 28 -item questionnaire proposes a four factor structure of empathy. This includes the understanding of others' thinking; Perspective Taking (PT), the ability to emotionally sympathise; Empathic Concern (EC), tendencies to empathise with fictional characters; Fantasizing $(\mathrm{FN})$ and the negative consequences of being sensitive to others; Personal Distress (PD). Hawk and colleagues (2013) investigated reliability of the IRI domains in a sample of 'early adolescents' (on average 13 years old), finding that PT ( $\alpha=.67)$, $\mathrm{EC}(\alpha=.70), \mathrm{FN}(\alpha=.78)$ and PD $(\alpha=.73)$ have acceptable internal reliability and comparable internal reliability was found here (see table 1).

Following the IRI, participants responded the 10-item Big Five Inventory (BFI-10, Rammstedt \& John, 2007). This measure of the Big Five has previously been used with populations with a similar age to the current sample (on average 14 years old; Freudenthaler, Spinath \& Neubauer, 2008). However, in the current study the internal reliabilities of this measure were poor $(\omega=.00$ to .51 , see table 1$)$. The poor consistency between the two items per domain, led us to drop this measure from the further analysis in the study.

The fourth questionnaire was the 14-item Implicit Theories of Intelligence Scale (ITIS; Abd-ElFattah \& Yates, 2006). This scale assesses participants' endorsements of 'Entity' Theories of Intelligence (that intelligence is a fixed property of a person) and 'Incremental' Theories of Intelligence (that intelligence is something flexible to be grown and developed). The Entity $(\alpha=.83)$ and Incremental $(\alpha=$ .75) theory scales have good internal reliability and the ITIS has been used with 13-16 year olds before (Abd-El-Fattah \& AL-Nabhani, 2012; Todor, 2014). The internal reliabilities of this scale were similar here (see table 1).

Finally, the pupils were asked to self-report their involvement with the five most disruptive behaviours reported in Infantino and Little's (2005) survey of 14-16 year old pupils. These behaviours 
Personality and Disruptive Behaviour

were; pupils talking unnecessarily in class, having an untidy uniform, disobeying the teacher, being aggressive to others in the class and being unpunctual. The pupils self-reported their frequency of engaging with these behaviours on a five point scale of Never (Rarely, Sometimes, Often) to Always, with Untidiness and Disobedience being presented in a positive frame ('My uniform is always smart and tidy' and 'I do exactly what the teacher says') and then reversed scored. In the current study, the selfreporting of these five behaviours were highly consistent (see table 1) and as such, we use an aggregate value of the disruptive behaviours as our main dependent variable for Self-Reported Disruptive behaviour ( $1=$ Never misbehaves, $5=$ Always Misbehaves $)$.

Teacher reports. The teachers also reported on the behaviour of the pupils using the same five item report scale (see above). The teachers also rated the pupils on the same frequency five point scale (Never to Always). As with the pupils, the teachers' reports of disruptive behaviour were highly consistent (see table 1). Initially the Teacher-Report Disruptive behaviour aggregate variable was retained for analysis, however the distribution of teacher-reported behaviour was highly skewed (1.72, see table 1). Further exploration of this distribution reveals that the teachers were using the scale in a largely binary fashion, whereby $49 \%$ of pupils received reports of 'never' engaging in the five disruptive behaviours (that is, the mean score $=1.00$ ) and others received a range of increasing engagement in disruptive behaviour. To best reflect the psychology of how the scale was used and to correct for potential issues in the skewed distribution (not correctable by transforming the distribution), a binary variable for teacher reporting of disruptive behaviour was retained. This scored pupils as engaging in no disruptive behaviour (1) or some disruptive behaviour (2).

\section{[Table 1 here]}

Analysis strategy. Analysis will be conducted in R and our code can be found on the OSF: https://osf.io/u2br4/?view_only=b3a8ac2ce2e84888904442dfcd9b44d7. As initial data checks, we will explore any variability in the reported disruptive behaviour due to the from which pupils were recruited. This will be tested with $\chi^{2}$ (from base R) and Cramer's V tests (from the 'MOTE' R package, Buchanan, 
Personality and Disruptive Behaviour

Gillenwaters, Scofield \& Valentine, 2019) for teacher-reported behaviour and Welch's t tests (using base R) and Cohen's d (from 'MOTE') tests for self-reported behaviour.

We will also explore the self-teacher agreement in the engagement with disruptive behaviour. To do this, we will build linear mixed models (using 'Ime4', Bates, Meachler, Bolker \& Walker, 2015) which will model teacher-reports (using binomial family linear mixed models) as a function of self-reports, accounting for the random effects of class nested in the random effects of school and participant gender. Computed odds ratios will supplement models of binary-coded teacher-reported behaviour.

For principle inferential analysis, we will test for correlations between the participants' traits and the disrupted behaviour reported in self- and teacher-reports (using 'jmv'). We will further build simultaneous linear mixed models to evaluate the relative strength of traits at predicting self- and teacherreported disruptive behaviour (using 'lme4') accounting for the random effects listed above.

For additional, conservative, analysis of the core psychological components in this data, we analyse the latent commonality of the scores to all trait domains. As there is a high degree of conceptual and statistical overlap between the traits of interest, oblique exploratory factor analysis (using a minimum residual oblimin 'fa' from 'psych', Revelle, 2019) were conducted on the overall trait scores to extract distinct sources of variance. These will then be used to build linear mixed models to predict disruptive behaviour with the aforementioned random effects.

We use a draw inference of significance from a criterion of $\alpha=.05$ for determining if an effect is notable. We report and draw inference from 95\% CI of effect sizes throughout our results.

\section{Results}

There were no notable differences in teacher-reported engagement with disruptive behaviour between the schools $\left(\chi^{2}(1)=1.00, p=0.318, V=.05[.00, .15]\right)$. There was a significant, albeit negligible, difference in self-reported behaviour $(t(139.97)=2.11, p=.037, d=0.20[0.02,0.045])$ and the mean response was approximately $2 / 5$ on the reports of engagement in disruptive behaviour in both of the schools. $\left(N_{1}=104, M_{1}=2.15, S D_{1}=0.79, N_{2}=353, M_{2}=1.97, S D_{2}=0.60\right)$. The inclusion of random effects of school and class in the linear mixed models analysis will provide insight into the extent to which the effects vary by school.

\section{Self-Teacher report agreement.}


Personality and Disruptive Behaviour

There was agreement between the self- and teacher-reported engagement in disruptive behaviour. This was the case when analysing the teacher binary classification of engages with disruptive behaviour or not $(\beta=1.10,95 \% \mathrm{CI}[0.27,1.93], p<.001, \mathrm{OR}=3.01,95 \% \mathrm{CI}[1.31,6.92])$ and when the teacherreported average score was used $(\beta=0.30,95 \% \mathrm{CI}[0.22,0.38], p<.001)$. Expressed as a correlation, this represents a relationship of $r=.30$ (95\% CI [.21, .38]. $p<.001)$.

\section{Personality and self-reported disrupted behaviour.}

Table 2 reports the relationship between personality and self-reported disruptive behaviour both in pairwise comparisons and simultaneous linear mixed models. There was convincing evidence of the BIS, empathic Perspective Taking, Empathic Concern and endorsing Incremental Theories of Intelligence all decreasing self-reported disruptive behaviour in the pairwise correlations. In the simultaneous model it was decreased BIS, Personal Distress and support for Incremental Theories of Intelligence scores that decreased self-reported disruptive behaviour. Converging evidence from these two forms of analysis would suggest that the anxiety-related inhibition and empathy traits, as well as, decreased belief in improvement over time relate to engaging in disruptive behaviours.

\section{Personality and teacher-reported disruptive behaviour.}

Table 2 also reports the relationship between personality and binary-coded teacher-reported engagement in disruptive behaviour (or not) using pairwise comparisons and simultaneous binomial linear mixed models. The pairwise relationships highlight a similar pattern of findings to the self-reported effects with decreased BIS, Perspective Taking and Incremental theories of intelligence being related to more teacher-reported disruptive behaviour. However, the more robust simultaneous model places most of the variance in teachers reporting that a pupil engages with disruptive behaviour to lower pupil endorsement of incremental theories of intelligence.

\section{Latent factors analyses.}

The average trait scores were inputted into an exploratory factor analysis to extract values reflective of the shared variance between similar traits. Largely, the exploratory factor analysis extracted factors representative of the three measures. Parallel analysis suggested a three-factor solution was adequate (eigenvalue $=.99$, explaining a cumulative $58 \%$ of the variance), with an acceptable model fit $(\mathrm{RMSEA}=0.0690 \% \mathrm{CI}[0.031,0.083], \mathrm{TLI}=.93)$. 
Personality and Disruptive Behaviour

The first extracted factor primarily consisted of the IRI traits of Empathic Concern (loading .91), Perspective Taking (.53), Fantasizing (.39), Personal Distress (.33) and the RST trait BAS (.31). All other traits loaded $<.30$ on this domain. This was termed 'Empathising' for further analysis.

The second factor featured only two of the RST traits as loading highly; BIS (.65) and FFFS (.66). For convenience, this factor was termed 'Avoidance', as an expression of how FFFS traits motivate avoidance of aversive stimuli and BIS traits motivate avoiding interaction.

The final factor, termed 'Responsiveness', was a combination of the ITIS traits (Incremental $=$ .50 , Entity $=-.36)$, low Personal Distress (-.59) and BAS (.33). Whilst a diverse set of constructs, these traits share dispositional tendencies to seek and respond positively to (potentially) adverse situations and challenge.

Derived scores from this factor solution were retained for analysis of the core shared phenomenon in the scales. In doing so, we mitigate risks of multiple tests of the same constructs in similar measures and offer a more conservative analysis of the relationship with disruptive behaviour.

Relationship with Self-reported behaviour. The three latent factors were all negative predictors of self-reported disruptive behaviour. Participants with higher Empathy $(\beta=-0.11,95 \% \mathrm{CI}[-0.19,-0.04]$, $p=.004)$, Avoidance $(\beta=-0.18,95 \% \mathrm{CI}[-0.27,-0.09], p<.001)$ and Responsiveness $(\beta=-0.20,95 \% \mathrm{CI}[-$ $0.27,-0.12], p<.001)$ reported less disruptive behaviour. In this model there was limited variance due to the random effects of class in school $(\mathrm{SD}=0.13)$ and gender of pupil $(\mathrm{SD}=0.05)$.

Relationship with Teacher-reported behaviour. For teacher-reported disruptive behaviour only lower Responsiveness $(\beta=-0.60,95 \% \mathrm{CI}[-0.92,-0.28], p<.001, \mathrm{OR}=0.55,95 \% \mathrm{CI}[0.40,0.76])$ and, to a lesser extent, Avoidance $(\beta=-0.46,95 \% \mathrm{CI}[-0.83,-0.09], p=.015$, OR= $0.63,95 \% \mathrm{CI}[0.44,0.91])$ scores indicated teacher-reports of engaging with disruptive behaviour. Empathy did not relate to teacherreports of disruptive behaviour $(\beta=-0.05,95 \% \mathrm{CI}[-0.25,0.35], p=.752, \mathrm{OR}=1.05,95 \% \mathrm{CI}[0.78,1.41])$. There was some variability by class in school $(\mathrm{SD}=1.21)$ but limited variability due to gender $(\mathrm{SD}=0.49)$

Gender differences in traits and behaviour. The gender differences in the traits, the latent factors and the self- and teacher-reported disruptive behaviour are reported in table 3 . The female participants in the sample scored higher on FFFS, BIS, Perspective Taking, Empathic Concern, Fantasizing empathy, and Personal Distress. This the differences are best summarised by the latent factors 
Personality and Disruptive Behaviour

which show female participants scoring higher on Empathy and Avoidance and lower on Responsiveness. The male participants overall self-reported more disruptive behaviour and were likely to be reported as engaging in any disruptive behaviour by their teachers.

\section{Discussion}

Pupils' normative personality traits explain variance in engaging with disruptive behaviour. This suggests that, beyond categorical diagnostic labels, there is meaningful insight in classroom conduct to be gained in considering the variability in pupils' personalities. Both teacher- and self-reports of disruptive behaviour suggested that lower Incremental Theories of Intelligence (the belief that intelligence is malleable) related to increased engagement with disruptive behaviour. Whilst there was self-teacher agreement on trends in reporting disruptive behaviour, the teachers' use of the scales was more polarised, with many of their reports stating that pupils to 'never' be engaging in any of the disruptive behaviours listed or engaged in some. The increased variability in the self-reports might explain how there was additional variance explained by the BIS and Personal Distress traits. However, the unique relationships in pupil reports could also be due to general patterns of responding and a more (BIS and Personal Distress-based) anxious pupil might be biased into reporting less disruption. Whilst the self-report traits effects are interesting, it is the convergence of the self- and teacher-report effects with Incremental theory endorsement that we consider robust.

As we had predicted there were also gender differences in disruptive behaviour and these reflected gender differences in the traits. Trait variability can be a more useful predictor of behaviour than gender differences alone, as there is sizeable variability in trait behaviour within gender categories, which can be missed with only discrete gender labels. For example, here, endorsement of incremental theories were not notably different between the genders of the pupils but the scores on the ITIS scale were. The gender differences found here reflect research on 'laddish', anti-learning cultures and particularly boys' underachievement (Francis, 1999; Jackson, 2002; 2003; Younger \& Warrington, 2005). According to Skelton and Francis (2003), boys may attempt to demonstrate their masculinity by adopting anti-school attitudes, becoming 'anti-heroes in the classroom' (p. 6). Jackson $(2002,2003)$ holds that boys may adopt self-handicapping strategies in learning environments to detract attention away from academic competition. According to Connolly (2004), there is currently limited research to investigate the 
Personality and Disruptive Behaviour

psychological underpinnings of why students adopt these 'laddish' behaviours, however the current study can add to this with the understanding that lower belief in the ability to learn lead to more disruption. As such laddishness could be seen as a dissociation with classroom norms.

It could be the case that our results are limited to our sample's age group. There is limited research on the effects of classroom behaviour in 11-16 year olds, which is a notably challenging time in the UK education system. This time at school is associated with greater choice and empowerment in learning but it is partnered with greater stakes than before. Pupils are aware of how their final qualifications at secondary school can affect future further education and occupational prospects. Due to these heightened risks, costs and choices, it could be the case that pupils in the later stages of mandatory education may behave differently in classroom settings. Further research is needed in this population to understand this complicated period, and the current findings may be typical of this age group in this stage of schooling.

This paper draws attention to the lack of detailed work trying to understand and predict how personality variation in a classroom may lead to behavioural differences in pupils. Research on disruptive behaviour tends to be focused on pupils with significantly atypical behavioural problems or neurodevelopmental disorders (e.g. Abikoff et al., 2002) For a long time the everyday behavioural consequences of personality have been overlooked (Furr, 2009) and, in a classroom setting, a better understanding of how individual differences in personality lead to individual differences in behaviour could offer opportunities for early intervention. In the current study empathy and rumination traits relate to less disruptive behaviour. It could be the case that interventions designed to target those traits and associated behaviours may help improve the conduct of pupils who are at risk of disruptive behaviour.

Conclusion. Overall, this study draws attention to the absence of research explaining the variance in disruptive behaviour using norm-based measures of individual differences psychology. We found evidence of natural variation in endorsing implicit theories and trait empathy being particularly important for understanding disruptive behaviour. It is not only those with diagnoses of conduct disorders that disrupt classrooms and so a more comprehensive approach to understanding how individual differences affect classroom conduct would benefit teachers, researchers and those delivering behavioural interventions. 
Personality and Disruptive Behaviour

\section{References}

Abd-El-Fattah, S. M., \& AL-Nabhani, H. Z. (2012). From Self-Theories of Intelligence to Academic Delay of Gratification: The Mediating Role of Achievement Goals. Australian Journal of Educational \& Developmental Psychology, 12, 93-107.

Abd-El-Fattah, S. M., \& Yates, G. C. R. (2006, November). Implicit theory of intelligence scale: Testing for factorial invariance and mean structure. Australian Association for Research in Education Conference. South Australia: Adelaide.

Abikoff, H. B., Jensen, P. S., Arnold, L. E., Hoza, B., Hechtman, L., Pollack, S., ... \& Vitiello, B. (2002). Observed classroom behavior of children with ADHD: Relationship to gender and comorbidity. Journal of Abnormal Child Psychology, 30(4), 349-359.

Aloe, A. M., Shisler, S. M., Norris, B. D., Nickerson, A. B., \& Rinker, T. W. (2014). A multivariate metaanalysis of student misbehavior and teacher burnout. Educational Research Review, 12, 30-44. doi:10.1016/j.edurev.2014.05.003

Bates, D., Mächler, M., Bolker, B., \& Walker, S. (2015). Fitting Linear Mixed-Effects Models Using lme4. Journal of Statistical Software, 67(1), 1-48. doi:10.18637/jss.v067.i01.

Baumann, C., \& Krskova, H. (2016). School discipline, school uniforms and academic performance. International Journal of Educational Management, 30(6), 1003-1029. doi:10.1108/ijem-09-20150118

Beaman, R., Wheldall, K., \& Kemp, C. (2007). Recent Research on Troublesome Classroom Behaviour: A Review. Australasian Journal of Special Education, 31(01), 45-60. doi:10.1017/s1030011200025586

Blackwell, L. S., Trzesniewski, K. H., \& Dweck, C. S. (2007). Implicit theories of intelligence predict achievement across an adolescent transition: A longitudinal study and an intervention. Child Development, 78(1), 246-263. doi:10.1111/j.1467-8624.2007.00995

Buchanan E, Gillenwaters A, Scofield J, Valentine K (2019)._MOTE: Measure of the Effect: Package to assist in effect size calculations and their confidence intervals_. R package version 1.0.2, http://github.com/doomlab/MOTE 
Personality and Disruptive Behaviour

Connolly, P. (2004). Boys and schooling in the early years. London: Routledge Falmer.

Cooper, A. J., Stirling, S., Dawe, S., Pugnaghi, G. \& Corr, P. J. (2017). The reinforcement sensitivity theory of personality in children: A new questionnaire. Personality and Individual Differences, 15, 65-69

Corr, P. J. (2004). Reinforcement sensitivity theory and personality. Neuroscience \& Biobehavioral Reviews, 28(3), 317-332. http://dx.doi.org/10.1016/j.neubiorev.2004. 01.005.

Corr, P. J. \& Cooper, A. (2016). The Reinforcement Sensitivity Theory of Personality Questionnaire (RST-PQ): Development and validation. Psychological Assessment, 28(11), 1427-1440.

Corr, P. J. \& McNaughton, N. (2015). Neural mechanisms of low trait anxiety and risk for externalizing behaviour. In T. Beauchaine \& S. Hinshaw (eds.), Oxford Handbook of Externalizing Spectrum Disorders: A Developmental Psychopathology Perspective (pp. 220-238). Oxford: Oxford University Press.

Davis, M. H. (1980). A multidimensional approach to individual differences in empathy. Catalog of Selected Documents in Psychology, 10, 85.

Davis, M. H. (1983). Measuring individual differences in empathy: Evidence for a multidimensional approach. Journal of Personality and Social Psychology, 44(1), 113-126. doi:10.1037/00223514.44.1.113

De Corte, K., Buysse, A., Verhofstadt, L. L., Roeyers, H., Ponnet, K., \& Davis, M. H. (2007). Measuring Empathic Tendencies: Reliability And Validity of the Dutch Version of the Interpersonal Reactivity Index. Psychologica Belgica, 47(4), 235. doi:10.5334/pb-47-4-235

Dweck, C. S. (1986). Motivational processes affecting learning. American Psychologist, 41(10), 10401048. doi:10.1037/0003-066X.41.10.1040

Dweck, C. S. (1999). Self-theories: Their role in motivation, personality, and development. Pennsylvania: Psychology Press.

Dweck, C. S., \& Elliott, E. S. (1983). Achievement motivation. In P. H. Mussen \& E. M. Hetherington (Eds.), Handbook of Child Psychology, (pp. 643-691). New York: Wiley.

Dweck, C. S., \& Leggett, E. L. (1988). A social-cognitive approach to motivation and personality. Psychological Review, 95(2), 256-273. doi:10.1037/0033-295X.95.2.256 
Personality and Disruptive Behaviour

Elliott, E. S., \& Dweck, C. S. (1988). Goals: An approach to motivation and achievement. Journal of Personality and Social Psychology, 54(1), doi:10.1037/0022-3514.54.1.5

Eysenck, S. B. G., \& Eysenck, H. J. (1978). Impulsiveness and venturesomeness: Their position in a dimensional system of personality description. Psychological Reports, 43(3), 1247-1255. http://dx.doi.org/10.2466/pr0.1978.43.3f.1247.

Finn, J. D., Pannozzo, G. M., \& Voelkl, K. E. (1995). Disruptive and inattentive-withdrawn behavior and achievement among fourth graders. The Elementary School Journal, 95(5), 421-434. doi:10.1086/461853

Francis, B. (1999). Lads, lasses and (new) labour: 14-16-year-old students' responses to the 'laddish behaviour and boys' underachievement' debate. British Journal of Sociology of Education, 20(3), 355-371. doi:10.1080/01425699995317

Freudenthaler, H. H., Spinath, B., \& Neubauer, A. C. (2008). Predicting school achievement in boys and girls. European Journal of Personality, 22(3), 231-245. doi:10.1002/per.678

Fry, P. S. (1983). Process measures of problem and non-problem children's classroom behaviour: the influence of teacher behaviour variables. British Journal of Educational Psychology, 51(1), 79-88. doi: 10.1111/j.2044-8279.1983.tb02537.x

Furr, R. M. (2009). Personality psychology as a truly behavioural science. European Journal of Personality, 23(5), 369-401. doi:10.1002/per.724

Ganimian, A. J. (2020). Growth-Mindset Interventions at Scale: Experimental Evidence From Argentina. Educational Evaluation and Policy Analysis, 42(3), 417-438.

Hawk, S. T., Keijsers, L., Branje, S. J. T., Graaff, J. V. der, Wied, M. de, \& Meeus, W. (2013). Examining the Interpersonal Reactivity Index (IRI) Among Early and Late Adolescents and Their Mothers. Journal of Personality Assessment, 95(1), 96-106. doi:10.1080/00223891.2012.696080

Hoskins, S. (Ed.). (2019). Growth Mindset for Teachers: Growing learners in the classroom. SAGE Publications Limited. 
Personality and Disruptive Behaviour

Houghton, S., Merrett, F., \& Wheldall, K. (1988). The attitudes of British secondary school pupils to praise, rewards, punishments and reprimands: A further study. New Zealand Journal of Educational Studies, 23, 203-214

Houghton, S., Wheldall, K., Jukes, R., \& Sharpe, A. (1990). The effects of limited private reprimands and increased private praise on classroom behaviour in four British secondary school classes. British Journal of Educational Psychology, 60(3), 255-265. doi:10.1111/j.2044-8279.1990.tb00943.x

Houghton, S., Wheldall, K., \& Merrett, F. (1988). Classroom behaviour problems which secondary school teachers say they find most troublesome. British Educational Research Journal, 14(3), 297312. doi:10.1080/0141192880140306

Infantino, J., \& Little, E. (2005). Students' perceptions of classroom behaviour problems and the effectiveness of different disciplinary methods. Educational Psychology, 25(5), 491-508. doi:10.1080/01443410500046549

Jackson, C. (2002). 'Laddishness' as a self-worth protection strategy. Gender and Education, 14(1), 37-50. doi:10.1080/09540250120098870

Jackson, C. (2003). Motives for 'laddishness' at school: Fear of failure and fear of the 'feminine'. British Educational Research Journal, 29(4), 583-598. doi:10.1080/01411920301847

Kaplan, A., Gheen, M., \& Midgley, C. (2002). Classroom goal structure and student disruptive behaviour. British Journal of Educational Psychology, 72(2), 191-211. doi:10.1348/000709902158847

Lawrence, J., Steed, D., \& Young, P. (1983). Monitoring teachers' reports of incidents of disruptive behaviour in two secondary schools: Multi-disciplinary research and intervention. Educational Studies, 9(2), 81-91. doi:10.1080/0305569830090202

Li, Y., \& Bates, T. C. (2020). Testing the association of growth mindset and grades across a challenging transition: Is growth mindset associated with grades?. Intelligence, 81, 101471.

Little, E. (2005). Secondary school teachers' perceptions of students' problem behaviours. Educational Psychology, 25(4), 369-377. doi:10.1080/01443410500041516 
Personality and Disruptive Behaviour

Little, E., Hudson, A., \& Wilks, R. (2002). The efficacy of written teacher advice (tip sheets) for managing classroom behaviour problems. Educational Psychology, 22(3), 251-266. doi:10.1080/01443410220138494

McCrae, R. R., \& Costa, P. T. (1987). Validation of the five-factor model of personality across instruments and observers. Journal of Personality and Social Psychology, 52(1), 81-90. doi:10.1037/0022-3514.52.1.81

McCrae, R. R., \& John, O. P. (1992). An introduction to the five-factor model and its applications. Journal of Personality, 60(2), 175-215. http://dx.doi.org/10.1111/j.1467-6494. 1992.tb00970.x.

Patalay, P., Fink, E., Fonagy, P., \& Deighton, J. (2015). Unpacking the associations between heterogeneous externalising symptom development and academic attainment in middle childhood. European Child \& Adolescent Psychiatry, 25(5), 493-500. doi:10.1007/s00787-015-0758-5

Pekrun, R., Goetz, T., Daniels, L. M., Stupnisky, R. H., \& Perry, R. P. (2010). Boredom in achievement settings: Exploring control-value antecedents and performance outcomes of a neglected emotion. Journal of Educational Psychology, 102(3), 531-549. doi:10.1037/a0019243

Rammstedt, B., \& John, O. P. (2007). Measuring personality in one minute or less: A 10- item short version of the Big Five Inventory in English and German. Journal of Research in Personality, 41(1), 203-212. http://dx.doi.org/10.1016/j.jrp.2006.02.001.

Revelle, W. (2019) psych: Procedures for Personality and Psychological Research, Northwestern University, Evanston, Illinois, USA, https://CRAN.R-project.org/package=psych Version = 1.9.12.

Roslyne Wilkinson, H., \& Jones Bartoli, A. (2020). Antisocial behaviour and teacher-student relationship quality: The role of emotion-related abilities and callous-unemotional traits. British Journal of Educational Psychology. doi:10.1111/bjep.12376

Rubin, K. H., Coplan, R. J., Nelson, L. J., Cheah, C. S. L., \& Lagace-Seguin, D. G. (1999). Peer relationships in childhood. In M. H. Bornstein \& M. E. Lamb (Eds.), Developmental psychology: An advanced textbook (4th ed., pp. 451-501). Mahwah, NJ: Erlbaum

Satchell, L., Hoskins, S., Corr, P., \& Moore, R. (2017). Ruminating on the nature of intelligence: Personality predicts implicit theories and educational persistence. Personality and Individual Differences, 113, 109-114. doi:10.1016/j.paid.2017.03.025 
Personality and Disruptive Behaviour

Selker, R., Love, J., \& Dropmann, D. (2017). jmv: The'jamovi'Analyses. R package version 1.2.23. https://CRAN.R-project.org/package=jmv

Sisk, V. F., Burgoyne, A. P., Sun, J., Butler, J. L., \& Macnamara, B. N. (2018). To what extent and under which circumstances are growth mind-sets important to academic achievement? Two metaanalyses. Psychological science, 29(4), 549-571.

Skelton, C., \& Francis, B. (2003). Boys and girls in the primary classroom. Maidenhead: Open University Press.

Todor, I. (2014). Investigating "The Old Stereotype” about Boys/Girls and Mathematics: Gender Differences in Implicit Theory of Intelligence and Mathematics Self-efficacy Beliefs. Procedia Social and Behavioral Sciences, 159, 319-323. doi:10.1016/j.sbspro.2014.12.380

Tremblay, R. E., Masse, B., Perron, D., Leblanc, M., Schwartzman, A. E., \& Ledingham, J. E. (1992). Early disruptive behavior, poor school achievement, delinquent behavior, and delinquent personality: Longitudinal analyses. Journal of Consulting and Clinical Psychology, 60(1), 64-72. doi:10.1037/0022-006x.60.1.64

Warren, F., Mason-Apps, E., Hoskins, S., Devonshire, V., \& Chanvin, M. (2019). The relationship between implicit theories of intelligence, attainment and socio-demographic factors in a UK sample of primary school children. British Educational Research Journal, 45(4), 736-754. doi: 10.1002/berj.3523

Wheldall, K. (1991). Managing troublesome classroom behaviour in regular schools: a positive teaching perspective. International Journal of Disability, Development and Education, 38(2), 99-116. doi:10.1080/0156655910380202

Younger, M., \& Warrington, M. (2005). Raising boys' achievement in secondary schools. Maidenhead: Open University Press.

Yves Rosseel (2012). lavaan: An R Package for Structural Equation Modeling. Journal of Statistical Software, 48(2), 1-36. URL http://www.jstatsoft.org/v48/i02/ 
Tables

Table 1. The descriptive statistics for the personality and behaviour measures used in this study.

\begin{tabular}{|c|c|c|c|c|c|c|}
\hline Response & Mean & SD & Minimum & Maximum & McDonald's $\omega$ & Skewness \\
\hline \multicolumn{7}{|c|}{ Child-Reinforcement Sensitivity Theory Personality Questionnaire } \\
\hline Fight/Flight/Freeze System & 2.85 & 0.77 & 1.00 & 5.00 & .74 & 0.05 \\
\hline Behavioural Inhibition & 3.19 & 0.76 & 1.00 & 4.86 & .82 & -0.35 \\
\hline Behavioural Approach & 4.00 & 0.59 & 1.00 & 5.00 & .80 & -0.92 \\
\hline \multicolumn{7}{|c|}{ Interpersonal Reactivity Index } \\
\hline Perspective Taking & 3.04 & 0.64 & 1.00 & 4.71 & .74 & -0.16 \\
\hline Empathic Concern & 3.47 & 0.62 & 1.00 & 5.00 & .75 & -0.53 \\
\hline Fantasizing & 2.95 & 0.69 & 1.29 & 5.00 & .73 & 0.24 \\
\hline Personal Distress & 3.03 & 0.61 & 1.14 & 5.00 & .71 & -0.08 \\
\hline \multicolumn{7}{|l|}{ Big Five Inventory-10 } \\
\hline Conscientiousness & 3.04 & 0.79 & 1.00 & 5.00 & .32 & 0.16 \\
\hline Agreeableness & 3.45 & 0.65 & 1.00 & 5.00 & .05 & -0.40 \\
\hline Neuroticism & 3.34 & 0.93 & 1.00 & 5.00 & .51 & -0.06 \\
\hline Openness & 3.30 & 0.72 & 1.00 & 5.00 & .00 & -0.10 \\
\hline Extraversion & 3.23 & 0.90 & 1.00 & 5.00 & .45 & 0.00 \\
\hline \multicolumn{7}{|c|}{ Implicit Theories of Intelligence Scale } \\
\hline Entity Theory & 2.89 & 0.58 & 1.00 & 4.71 & .66 & -0.06 \\
\hline Incremental Theory & 3.54 & 0.50 & 1.00 & 5.00 & .71 & -0.75 \\
\hline \multicolumn{7}{|c|}{ Disruptive Behaviour Frequency (mean score of raw items) } \\
\hline Self-Reported & 2.01 & 0.66 & 1.00 & 5.00 & .74 & 1.07 \\
\hline Teacher-Reported & 1.43 & 0.63 & 1.00 & 4.20 & .86 & 1.72 \\
\hline
\end{tabular}

Note. All scales are responded to on a scale of 1 (minimum) to 5 (maximum). 
Personality and Disruptive Behaviour

Table 2. The pairwise correlations and simultaneous linear mixed model effects for the traits predicting self-and teacher-reported disruptive behaviour in this study.

\begin{tabular}{|c|c|c|c|c|}
\hline \multirow[b]{2}{*}{ Trait } & \multicolumn{2}{|c|}{ Pairwise correlation $r[95 \% C I]$} & \multicolumn{2}{|c|}{ Model estimate $\beta[95 \% \mathrm{CI}]$} \\
\hline & Self-report & Teacher-report & Self-report ${ }^{\mathrm{a}}$ & Teacher-report ${ }^{\mathrm{b}}$ \\
\hline \multicolumn{5}{|c|}{ Child-Reinforcement Sensitivity Theory Personality Questionnaire } \\
\hline FFFS & $-.07[-.15, .02]$ & $-.10[-.19,-.01]^{*}$ & $0.04[-0.05,0.13]$ & $-0.04[-0.40,0.33]$ \\
\hline BIS & $-.33[-.41,-.24] * * *$ & $-.18[-.26,-.09] * * *$ & $-0.19[-0.28,-0.10]^{* * *}$ & $-0.22[-0.58,0.14]$ \\
\hline BAS & $-.11[-.20,-.02]^{*}$ & $-.03[-.13, .06]$ & $0.04[-0.06 .0 .15]$ & $0.04[-0.39,0.46]$ \\
\hline \multicolumn{5}{|c|}{ Interpersonal Reactivity Index } \\
\hline PT & $-.29[-.37,-.21] * * *$ & $-.11[-.20,-.02]^{*}$ & $-0.15[-0.26,-0.04]$ & $-0.32[-0.78,0.13]$ \\
\hline $\mathrm{EC}$ & $-.27[-.36,-.19] * * *$ & $-.07[-.16, .02]$ & $-0.07[-0.19,0.06]$ & $0.51[-0.12,0.93]$ \\
\hline Fantasizing & $-.11[-.20,-.02]^{*}$ & $-.15[-.23,-.05]^{* *}$ & $0.07[-0.03,0.16]$ & $-0.17[-0.53,0.20]$ \\
\hline $\mathrm{PD}$ & $-.09[-.00,-.18]^{*}$ & $-.02[-.11, .07]$ & $-0.02[-0.14,0.10]^{* *}$ & $0.04[-0.45,0.53]$ \\
\hline \multicolumn{5}{|c|}{ Implicit Theories of Intelligence Scale } \\
\hline Entity & $.15[.06, .24]^{* *}$ & $.09[-.00, .18]$ & $0.11[0.00,0.22]^{*}$ & $0.28[-0.16,0.72]$ \\
\hline Incremental & $-.32[-.40,-.24] * * *$ & $-.21[-.29,-.12] * * *$ & $-0.28[-0.40,-0.15]^{* * *}$ & $-0.81[-1.36,-0.25]^{* * *}$ \\
\hline
\end{tabular}

Notes.

Uncorrected $p$ values are reported $* p<.05, * * p<.01, * * * p<.001$

FFFS= Fight/Flight/Freeze System, BIS= Behavioural Inhibition System, BAS=Behavioural Approach System, PT= Perspective Taking, EC= Empathic Concern, $\mathrm{PD}=$ Personal Distress

${ }^{a}$ All traits entered simultaneously into a linear mixed model containing the random effects of class nested in school $(\mathrm{SD}=$ $0.14)$ and gender $(\mathrm{SD}=0.06)$.

${ }^{\mathrm{b}}$ All traits entered simultaneously into a binomial family general linear mixed model containing the random effects of class nested in school $(\mathrm{SD}=1.20)$ and gender $(\mathrm{SD}=0.47)$. 
Personality and Disruptive Behaviour

Table 3. Gender differences in the variables used in this study

\begin{tabular}{lrrr}
\hline Measure & Difference $t(p) d[95 \% \mathrm{CI}]$ & $\mathrm{M}(\mathrm{SD})$ Female & M (SD) Male \\
\hline Child-Reinforcement Sensitivity Theory Personality Questionnaire & & \\
FFFS & $9.86(<.001) 1.00[0.79,1.21]^{*}$ & $3.23(0.76)$ & $2.51(0.68)$ \\
BIS & $4.76(<.001) 0.48[0.28,0.68]^{*}$ & $3.38(0.73)$ & $3.01(0.81)$ \\
BAS & $-0.41(.683) 0.04[-0.16,0.24]^{*}$ & $3.98(0.55)$ & $4.01(0.69)$ \\
Interpersonal Reactivity Index & & \\
PT & $4.08(<.001) 0.41[0.21,0.61]^{*}$ & $3.17(0.67)$ & $2.90(0.65)$ \\
EC & $5.76(<.001) 0.58[0.38,0.78]^{*}$ & $3.63(0.58)$ & $3.28(0.65)$ \\
Fantasizing & $3.50(<.001) 0.35[0.15,0.55]^{*}$ & $3.06(0.70)$ & $2.81(0.73)$ \\
PD & $8.73(<.001) 0.88[0.67,1.09]^{*}$ & $3.29(0.58)$ & $2.79(0.55)$ \\
Implicit Theories of Intelligence Scale & & \\
Entity & $1.98(.049) 0.20[0.00,0.40]$ & $2.96(0.59)$ & $2.84(0.60)$ \\
Incremental & $0.90(.371) 0.09[-0.11,0.29]$ & $3.54(0.44)$ & $3.49(0.61)$ \\
Latent factors & & & \\
Empathy & $6.40(<.001) 0.65[0.44,0.85]^{*}$ & $0.27(0.86)$ & $-0.32(0.96)$ \\
Avoidance & $10.13(<.001) 1.03[0.81,1.23]^{*}$ & $0.39(0.70)$ & $-0.39(0.82)$ \\
Responsiveness & $-6.20(<.001) 0.63[0.42,0.83]^{*}$ & $-0.27(0.76)$ & $0.23(0.82)$ \\
Disruptive Behaviour & & & \\
Self-reported & $-3.18(<.001) 0.32[0.12,0.52]^{*}$ & $1.95(0.61)$ & $2.16(0.72)$ \\
Teacher-reported ${ }^{a}$ & $19.39(<.001) 0.21[0.12,0.30]^{*}$ & $42 \%$ AnyDisruptive & $65 \%$ AnyDisruptive \\
\hline
\end{tabular}

Notes $*$ denotes $p<.001$ as a conservative significance for multiple testing.

ain this case the difference value is $\chi^{2}$ with $95 \%$ CI of Cramer's $V$ 